\title{
On culture artefacts in coccolith morphology
}

\author{
Gerald Langer · Kerstin Oetjen · Tina Brenneis
}

Received: 11 January 2012/Revised: 31 July 2012/Accepted: 9 August 2012/Published online: 5 September 2012

(C) Springer-Verlag and AWI 2012

\begin{abstract}
Coccolith malformations occur more frequently in cultured specimens than in specimens from natural samples, a phenomenon commonly termed 'culture artefacts'. The causes of culture artefacts are unknown. Here, we tested the effect of culture flask shape, mixing, and cell density on the morphology of Emiliania huxleyi coccoliths. While there was no effect of different culture flask types typically used in coccolithophore culturing, continuous mixing reduced the percentage of malformations by ca. $11 \%$ in exponential-phase cells (cell density ca. $80 \times 10^{3}$ cells per $\mathrm{ml}$ ) and ca. $17 \%$ in stationary-phase cells (cell density ca. $2 \times 10^{6}$ cells per $\mathrm{ml}$ ). Stationary-phase cells displayed $19 \%$ more malformations than mid-exponentialphase cells when not mixed at all and $20 \%$ more malformations when continuously mixed. It is concluded that the lack of mixing and unnaturally high cell densities, typical for coccolithophore stock cultures, are partly responsible for culture artefacts.
\end{abstract}

Keywords Emiliania huxleyi - Coccolith morphology · Culture artefacts

Communicated by H.-D. Franke.

G. Langer $(\bowtie)$

Department of Earth Sciences, Cambridge University,

Downing St., Cambridge CB2 3EQ, UK

e-mail: g1345@cam.ac.uk

K. Oetjen - T. Brenneis

Biogeosciences, Alfred Wegener Institute for Polar and Marine Research, 27570 Bremerhaven, Germany

\section{Introduction}

Coccolithophores, unicellular haptophyte algae, surround themselves with a sphere consisting of coccoliths, elaborately crafted calcareous platelets. Coccolith-calcite is, besides foraminiferal calcite, the most important pelagic source of calcium carbonate (Baumann et al. 2004). The latter feature, amongst others, renders coccolithophore biology in general and coccolith production in particular a topic of broad interest. Over the last decade, the potential response of coccolithophores to ocean acidification (Royal Society 2005) has received special attention. Ocean acidification refers to the decrease in sea surface water $\mathrm{pH}$ caused by anthropogenic $\mathrm{CO}_{2}$ emissions and the subsequent uptake of $\mathrm{CO}_{2}$ by the oceans. In a seminal study, it was first put forth that coccolith malformations (for details, see below) increase with increasing $\mathrm{CO}_{2} /$ decreasing $\mathrm{pH}$ in a particular culture strain of Emiliania huxleyi (Riebesell et al. 2000). The latter observation gave rise to the notion that coccolith malformations can be used as an indicator of ocean acidification. Subsequently, the applicability of laboratory observations to the coccolith sedimentary record was explored using a, with respect to morphology, particularly sensitive species (Langer et al. 2006). Recently, it was argued that coccolith malformations in response to ocean acidification are crucial to the question of how coccolithophores will perform in an acidifying ocean (Langer et al. 2011).

Malformation was defined as irregular coccolith formation as a result of departure from the normal growth process (i.e. teratological malformation)' (Young and Westbroek 1991). This implies that malformation is the result of a malfunction of the coccolith-shaping machinery per se, and therewith, incompleteness of a coccolith is not to be regarded as a malformation (Young and 
Westbroek 1991). Either malformed coccoliths typically display a reduced symmetry (see Young and Westbroek 1991) or the shape of individual elements is changed (Young and Westbroek 1991) (Fig. 2). The latter criterion was used in this study, because reduced symmetry was too inconspicuous to be unambiguously identifiable.

In view of the fact that culture experiments are the prime tool to investigate organism's responses to changing seawater carbonate chemistry, there is the obvious need to answer the question why coccolith malformations occur more frequently in cultured specimens than in specimens from natural samples (Langer et al. 2006; Langer and Benner 2009), a phenomenon commonly termed 'culture artefacts'. No solution to this problem has been discovered yet. It was shown that sub-optimal light and temperature conditions do not induce malformations in one culture strain of E. huxleyi, one of the most prominent coccolithophore (Langer et al. 2010). Another strain of E. huxleyi, however, displayed a higher percentage of malformations at sub-optimal temperature (Watabe and Wilbur 1966). It is difficult to decide which of these two responses to temperature is representative of E. huxleyi or even coccolithophores in general. The potential influence of temperature on coccolith morphology is currently under investigation in our laboratory, but shall not be the subject matter of this paper.

Coccolithophore cultures are typically so-called batch cultures (Probert and Houdan 2004). Briefly, the latter usually feature 50-250-ml culture flasks, in which the cells are grown up to the maximally possible cell density. This is ensured by unnaturally high nutrient concentrations that are achieved through seawater additives (Probert and Houdan 2004). Hence, coccolithophores in culture experience exponential as well as stationary growth phases. The maximal cell density, at which the stationary phase is reached, is species specific. The particular reason for the cessation of cell division (i.e. stationary growth phase) is largely unknown, because there are many possibilities, for example, micronutrient limitation, accumulation of toxic waste products, and altered carbonate chemistry. Normal coccolithophore stock cultures are rarely, if at all, mixed, resulting in sedimentation of the cells. So, there are several ways in which coccolithophore cultures are artificial; these include unnaturally high nutrient concentrations and therewith cell densities, the lack of mixing and concomitant sedimentation of cells, and the confinement in a small culture flask.

Since media additives for culturing coccolithophores usually contain unnaturally high nitrate concentrations (Probert and Houdan 2004), it was hypothesized that these elevated nitrate concentrations cause malformations, but in the case of E. huxleyi, it was shown that this is not so (Langer and Benner 2009). Apart from a brief treatment in
Probert and Houdan (2004), generally neglected points in the context of culturing of coccolithophores are the shape of the culture flasks, the mixing of the culture, and the cell density. Considering the fact that coccolithophores are planktonic organisms living in ocean surface waters, it is reasonable to hypothesize that the sedentary life these algae are forced to lead in a culture flask is stressful. Moreover, usual stock-culture cell densities are an order of magnitude higher than cell densities even in E. huxleyi blooms (Birkenes and Braarud 1952). It is not known whether coccolith morphogenesis is influenced by flask shape, mixing, and cell density. Therefore, we tested the effect of culture flask shape, mixing, and cell density on the morphology of E. huxleyi coccoliths.

\section{Materials and methods}

Clonal cultures of E. huxleyi [strain CCMP1516, obtained from the CCMP Culture Collection (https://ccmp.bigelow. org/)] were grown in aged (3 months), sterile-filtered (0.2- $\mu \mathrm{m}$-pore-size cellulose-acetate filters, Sartorius) North Sea seawater enriched with $880 \mu \mathrm{mol} \mathrm{l}^{-1}$ nitrate, $35 \mu \mathrm{mol} 1^{-1}$ phosphate, and trace metals and vitamins as in f/2 medium (Guillard and Ryther 1962). Cultures were grown under a 16/8 h light/dark cycle. Experiments were carried out at an average light intensity of $150 \mu \mathrm{mol}$ photons $\mathrm{m}^{-2} \mathrm{~s}^{-1}$ and a temperature of $18{ }^{\circ} \mathrm{C}$ in a temperature-controlled room. Salinity, measured with a conductivity meter (WTW Multi 340i) combined with a TetraCon 325 sensor, was 32. Cells were acclimated to experimental conditions for approximately 12 generations and subsequently grown in dilute batch cultures and batch cultures. The acclimation consisted of two times six generations grown to a final cell density of ca. 50,000 cells ml ${ }^{-1}$ each. Conditions of the cells in acclimation were identical to the experimental conditions. Each data point presented in the tables and figures is the mean value of triplicate culture experiments.

Cells were grown in flasks typically used in coccolithophore culturing. For reference images of the flasks used, see Fig. 1. Cultures were only manually mixed immediately before sampling for cell density. The following treatments characterized the experimental set-up (for a summary, see Table 1). (1a) Corning culture flask (polystyrene (PS), $250 \mathrm{ml}$ ) horizontal position (Fig. 1a); same as 2, but in addition to coccolith morphology, carbonate chemistry of seawater was monitored; early exponential growth phase. (1b) Corning culture flask (PS, $250 \mathrm{ml}$ ) horizontal position; same as 2 , but in addition to coccolith morphology, carbonate chemistry of seawater was monitored; late exponential growth phase. (1c) Corning culture flask (PS, $250 \mathrm{ml}$ ) horizontal position; same as 2 , but in addition to coccolith morphology, carbonate 
Fig. 1 Photographs of the culture flasks used in this study. a Corning culture flask (polystyrene (PS), $250 \mathrm{ml}$ ) horizontal position. b Corning culture flask (PS, $250 \mathrm{ml}$ ) vertical position. c Erlenmeyer flask (polycarbonate (PC), $250 \mathrm{ml}$. d Conical centrifuge flask horizontal position (PC, $175 \mathrm{ml})$
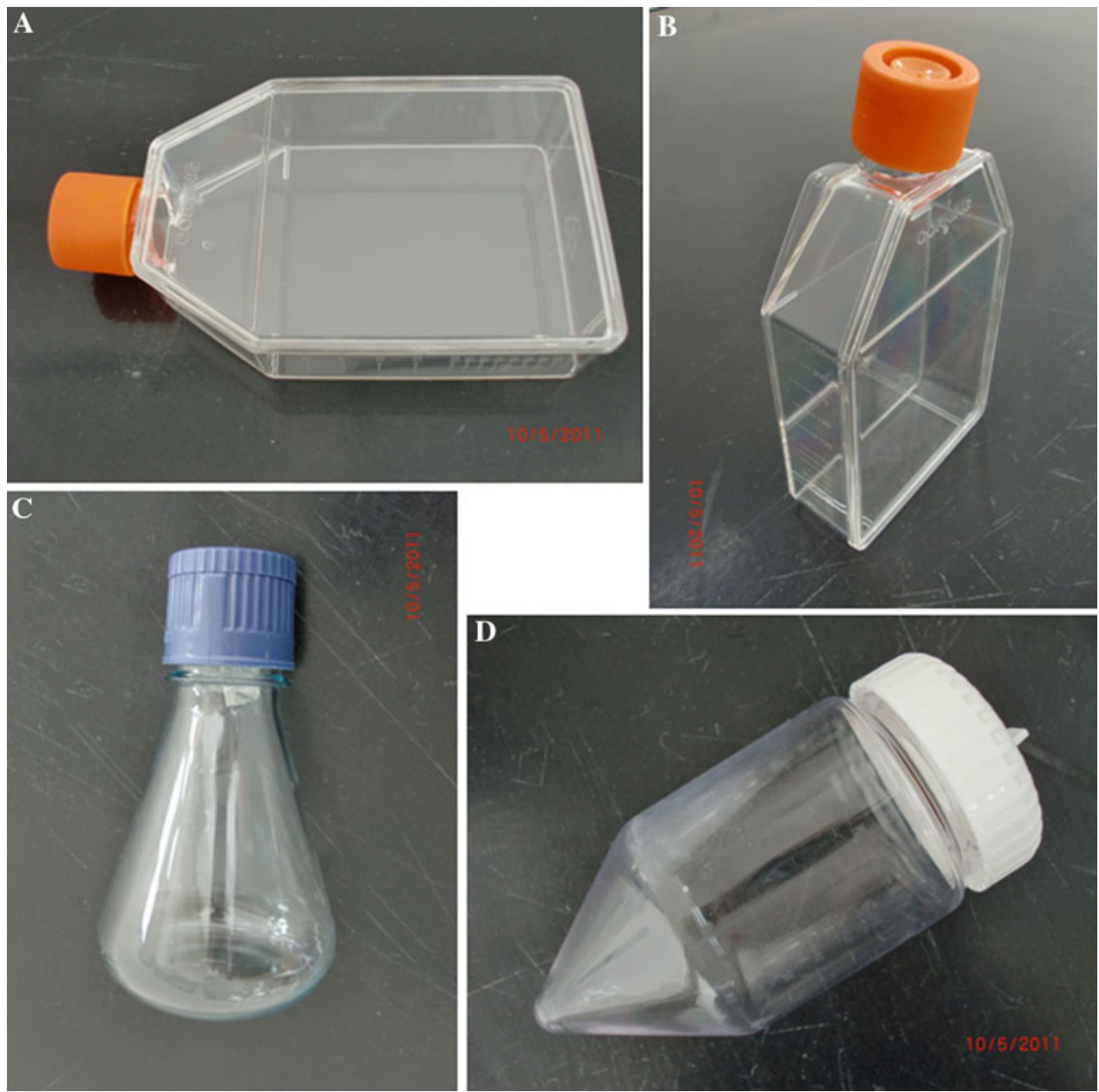

chemistry of seawater was monitored; beginning of stationary growth phase. (1d) Corning culture flask (PS, $250 \mathrm{ml}$ ) horizontal position; same as 2, but in addition to coccolith morphology, carbonate chemistry of seawater was monitored; 3 weeks into stationary growth phase. (2a) Corning culture flask (PS, $250 \mathrm{ml}$ ) horizontal position, exponential growth phase. (2b) Corning culture flask (PS, $250 \mathrm{ml}$ ) horizontal position (Fig. 1a), stationary growth phase. (3a) Corning culture flask (PS, $250 \mathrm{ml}$ ) vertical position (Fig. 1b), exponential growth phase. (3b) Corning culture flask (PS, $250 \mathrm{ml}$ ) vertical position (Fig. 1b), stationary growth phase. (4a) Conical centrifuge flask vertical position (PS, $175 \mathrm{ml}$, Fig. 1d), exponential growth phase. (4b) Conical centrifuge flask vertical position (PS, $175 \mathrm{ml}$, Fig. 1d), stationary growth phase. (5a) Erlenmeyer flask (polycarbonate (PC), $250 \mathrm{ml}$, Fig. 1c) static, exponential growth phase. (5b) Erlenmeyer flask (PC, $250 \mathrm{ml}$, Fig. 1c) static, stationary growth phase. (6a) Erlenmeyer flask (PC, $250 \mathrm{ml})$ attached to a rotating wheel $(30 \mathrm{~cm}$ diameter, $10 \mathrm{rpm}$ ), exponential growth phase. (6b) Erlenmeyer flask $(\mathrm{PC}, 250 \mathrm{ml})$ attached to a rotating wheel $(30 \mathrm{~cm}$ diameter, $10 \mathrm{rpm})$, stationary growth phase. (7a) Erlenmeyer flask
(PC, $250 \mathrm{ml}$ ) attached to a rotating wheel, during light phase; static during dark phase (30 $\mathrm{cm}$ diameter, $10 \mathrm{rpm}$ ), exponential growth phase. (7b) Erlenmeyer flask (PC, $250 \mathrm{ml}$ ) attached to a rotating wheel, during light phase; static during dark phase $(30 \mathrm{~cm}$ diameter, $10 \mathrm{rpm})$, stationary growth phase. (8a) Erlenmeyer flask (PC, $250 \mathrm{ml}$ ) on a shaker table (IKA Labortechnik Juergens KS 125 basic, 350-400 rpm), exponential growth phase. (8b) Erlenmeyer flask (PC, $250 \mathrm{ml}$ ) on a shaker table (IKA Labortechnik Juergens KS 125 basic, 350-400 rpm), stationary growth phase. (9a) Erlenmeyer flask (PC, $250 \mathrm{ml}$ ) on a shaker table, during light phase; static during dark phase (IKA Labortechnik Juergens KS 125 basic, 350-400 rpm), exponential growth phase. (9b) Erlenmeyer flask (PC, $250 \mathrm{ml}$ ) on a shaker table, during light phase; static during dark phase (IKA Labortechnik Juergens KS 125 basic, 350-400 rpm), stationary growth phase. (10a) Conical centrifuge flask horizontal position (PC, $175 \mathrm{ml}$ ), exponential growth phase. (10b) Conical centrifuge flask horizontal position (PC, $175 \mathrm{ml}$ ), stationary growth phase. (11a) Conical centrifuge flask horizontal position (PS, $175 \mathrm{ml}$ ), exponential growth phase. (11b) Conical 
Table 1 Summary of treatments

\begin{tabular}{|c|c|c|c|c|c|c|}
\hline Sample number & Flask type & Material & $\begin{array}{l}\text { Volume } \\
(\mathrm{ml})\end{array}$ & $\begin{array}{l}\text { Position during } \\
\text { light phase }\end{array}$ & $\begin{array}{l}\text { Position during } \\
\text { dark phase }\end{array}$ & Growth phase \\
\hline $1 \mathrm{a}$ & Corning culture flask & Polystyrene (PS) & 250 & Horizontal/static & Horizontal/static & Mid-exponential \\
\hline $1 b$ & Corning culture flask & Polystyrene (PS) & 250 & Horizontal/static & Horizontal/static & Late-exponential \\
\hline $1 \mathrm{c}$ & Corning culture flask & Polystyrene (PS) & 250 & Horizontal/static & Horizontal/static & Stationary \\
\hline $1 d$ & Corning culture flask & Polystyrene (PS) & 250 & Horizontal/static & Horizontal/static & 3 weeks stationary \\
\hline $2 \mathrm{a}$ & Corning culture flask & Polystyrene (PS) & 250 & Horizontal/static & Horizontal/static & Mid-exponential \\
\hline $2 b$ & Corning culture flask & Polystyrene (PS) & 250 & Horizontal/static & Horizontal/static & Stationary \\
\hline $3 \mathrm{a}$ & Corning culture flask & Polystyrene (PS) & 250 & Vertical/static & Vertical/static & Mid-exponential \\
\hline $3 b$ & Corning culture flask & Polystyrene (PS) & 250 & Vertical/static & Vertical/static & Stationary \\
\hline $4 a$ & Conical centrifuge flask & Polystyrene (PS) & 175 & Vertical/static & Vertical/static & Mid-exponential \\
\hline $4 \mathrm{~b}$ & Conical centrifuge flask & Polystyrene (PS) & 175 & Vertical/static & Vertical/static & Stationary \\
\hline $5 \mathrm{a}$ & Erlenmeyer flask & Polycarbonate (PC) & 250 & Vertical/static & Vertical/static & Mid-exponential \\
\hline $5 b$ & Erlenmeyer flask & Polycarbonate (PC) & 250 & Vertical/static & Vertical/static & Stationary \\
\hline $6 a$ & Erlenmeyer flask & Polycarbonate (PC) & 250 & Rotating wheel & Rotating wheel & Mid-exponential \\
\hline $6 b$ & Erlenmeyer flask & Polycarbonate (PC) & 250 & Rotating wheel & Rotating wheel & Stationary \\
\hline $7 \mathrm{a}$ & Erlenmeyer flask & Polycarbonate (PC) & 250 & Rotating wheel & Static & Mid-exponential \\
\hline $7 b$ & Erlenmeyer flask & Polycarbonate (PC) & 250 & Rotating wheel & Static & Stationary \\
\hline $8 a$ & Erlenmeyer flask & Polycarbonate (PC) & 250 & Shaker table & Shaker table & Mid-exponential \\
\hline $8 b$ & Erlenmeyer flask & Polycarbonate (PC) & 250 & Shaker table & Shaker table & Stationary \\
\hline $9 \mathrm{a}$ & Erlenmeyer flask & Polycarbonate (PC) & 250 & Shaker table & Static & Mid-exponential \\
\hline $9 b$ & Erlenmeyer flask & Polycarbonate (PC) & 250 & Shaker table & Static & Stationary \\
\hline $10 \mathrm{a}$ & Conical centrifuge flask & Polycarbonate (PC) & 175 & Horizontal/static & Horizontal/static & Mid-exponential \\
\hline $10 \mathrm{~b}$ & Conical centrifuge flask & Polycarbonate (PC) & 175 & Horizontal/static & Horizontal/static & Stationary \\
\hline $11 \mathrm{a}$ & Conical centrifuge flask & Polystyrene (PS) & 175 & Horizontal/static & Horizontal/static & Mid-exponential \\
\hline $11 \mathrm{~b}$ & Conical centrifuge flask & Polystyrene (PS) & 175 & Horizontal/static & Horizontal/static & Stationary \\
\hline
\end{tabular}

centrifuge flask horizontal position (PS, $175 \mathrm{ml}$ ), stationary growth phase.

Low cell densities in the dilute batch cultures $\left(<80,000\right.$ cells ml$\left.{ }^{-1}\right)$ even at the termination of the experiments resulted in a quasi-constant carbonate system over the course of the experiment (Langer et al. 2007; Langer and Benner 2009). High final cell densities (ca. $2 \times 10^{6}$ cells ml ${ }^{-1}$ ) in the batch cultures led to an alteration in the carbonate system (for details, see 'Results and discussion'). Briefly, in dilute batch cultures, typically $2-4 \%$ of the DIC is consumed, resulting in a pH shift of $0.03-0.05$ units. In batch cultures, ca. $65 \%$ of the DIC is consumed, resulting in a $\mathrm{pH}$ shift of ca. 1.3 units.

Samples for alkalinity measurements were filtered through $0.6-\mu \mathrm{m}$ nominal pore-size glass fibre filters (Whatman GF/F), poisoned with $1 \mathrm{ml} 35 \mathrm{~g} \mathrm{l}^{-1} \mathrm{HgCl}_{2}$, and stored in acid-washed $300-\mathrm{ml}$ borosilicate flasks at $0{ }^{\circ} \mathrm{C}$. DIC samples were sterile-filtered through $0.2-\mu \mathrm{m}$-pore-size cellulose-acetate syringe filters and stored in acid-washed 13-ml borosilicate flasks free of air bubbles at $0{ }^{\circ} \mathrm{C}$. Samples were measured within 2 days after sampling, which ensures constant DIC during storage total alkalinity (TA) was calculated from linear Gran plots (Gran 1952) after potentiometric titration (in duplicate) (Bradshaw et al. 1981; Brewer et al. 1986). DIC was measured photometrically (Stoll et al. 2001) in triplicate by means of a QuaAAtro autoanalyzer (Seal Analytical, Mequon, USA). Certified Reference Materials (Batch No. 54) supplied by A. Dickson were used to correct for inaccuracies of the measurements. Shifts in DIC concentrations due to $\mathrm{CO}_{2}$ exchange were prevented by opening the storage vials less than $1 \mathrm{~min}$ prior to each measurement. Samples for $\mathrm{pH}$ measurements were sterile-filtered through $0.2-\mu \mathrm{m}$-poresize cellulose-acetate syringe filters and measured potentiometrically using a glass electrode (Schott Instruments, Mainz, Germany) and a WTW pH meter. Calibration was performed using NBS buffers. The measured $\mathrm{pH}_{\mathrm{NBS}}$ values were converted to the total scale using respective Certified Reference Materials (Tris-based $\mathrm{pH}$ reference material, Batch No. 2, Scripps Institution of Oceanography, USA; see also Dickson 2010). All pH values are reported on the total scale.

The carbonate system was calculated from temperature, salinity, TA, pH (total scale), and phosphate using the DOS program $\mathrm{CO}_{2}$ sys (Lewis and Wallace 1998). The equilibrium constants of Mehrbach et al. (1973) refitted by 
Dickson and Millero (1987) were used. For determination of cell density, samples were taken daily or every other day and counted immediately after sampling using a Coulter Multisizer III (Beckman Coulter GmbH, Krefeld, Germany). Cell densities were plotted versus time, and growth rate $(\mu)$ was calculated from exponential regression using the natural logarithm. For estimating the fraction of culture flask area covered in cells, we assumed that all cells present in the flask sit on the bottom. The area covered by a single cell was estimated by calculating the area of a circle using the radius of the cell obtained from the Coulter Counter measurements.

Samples for scanning electron microscope analysis were filtered onto polycarbonate filters $(0.8 \mu \mathrm{m}$ pore size $)$, dried in a drying cabinet at $60{ }^{\circ} \mathrm{C}$ for $24 \mathrm{~h}$, and then sputtercoated with gold-palladium. Imaging was performed with a Philips XL-30 digital scanning field-emission electron microscope. Four categories were used to describe the morphology of E. huxleyi: 'normal', 'malformed 1', 'malformed 2', and 'incomplete' coccoliths (Young 1994); for reference images for the categories, see Fig. 2. An average of approximately 350 coccoliths was analysed per sample (Langer and Benner 2009). Classification of the coccoliths was made on captured images by all authors.
To avoid operator bias, samples were randomized and blind double counts were undertaken. These measures ensure robust, unbiased results (Langer et al. 2006; Langer and Benner 2009; Langer and Bode 2011; Langer et al. 2011; Langer et al. 2012). Recently, it was shown that results based on an objective, biometrical malformation index compare well with the classical, subjective categorization (Bach et al. 2012).

\section{Results}

The results of the cell counts and morphological analysis are summarized in Table 2. The carbonate chemistry of treatment 1 is summarized in Table 3. Since not all flasks available were made of polystyrene, we used polycarbonate flasks as well. This made it necessary to test the effect of flask material. Cells produced $73 \%$ normal coccoliths in the polycarbonate flask and $68 \%$ in the polystyrene flask (Fig. 3). Mixing of exponential-phase cells during the light phase only resulted in an increase in normal coccoliths of 5 and $7 \%$ (Fig. 4). Mixing of exponential-phase cells by means of a shaker table led to an increase in normal coccoliths of $5 \%$ (mixing during the light phase only) and
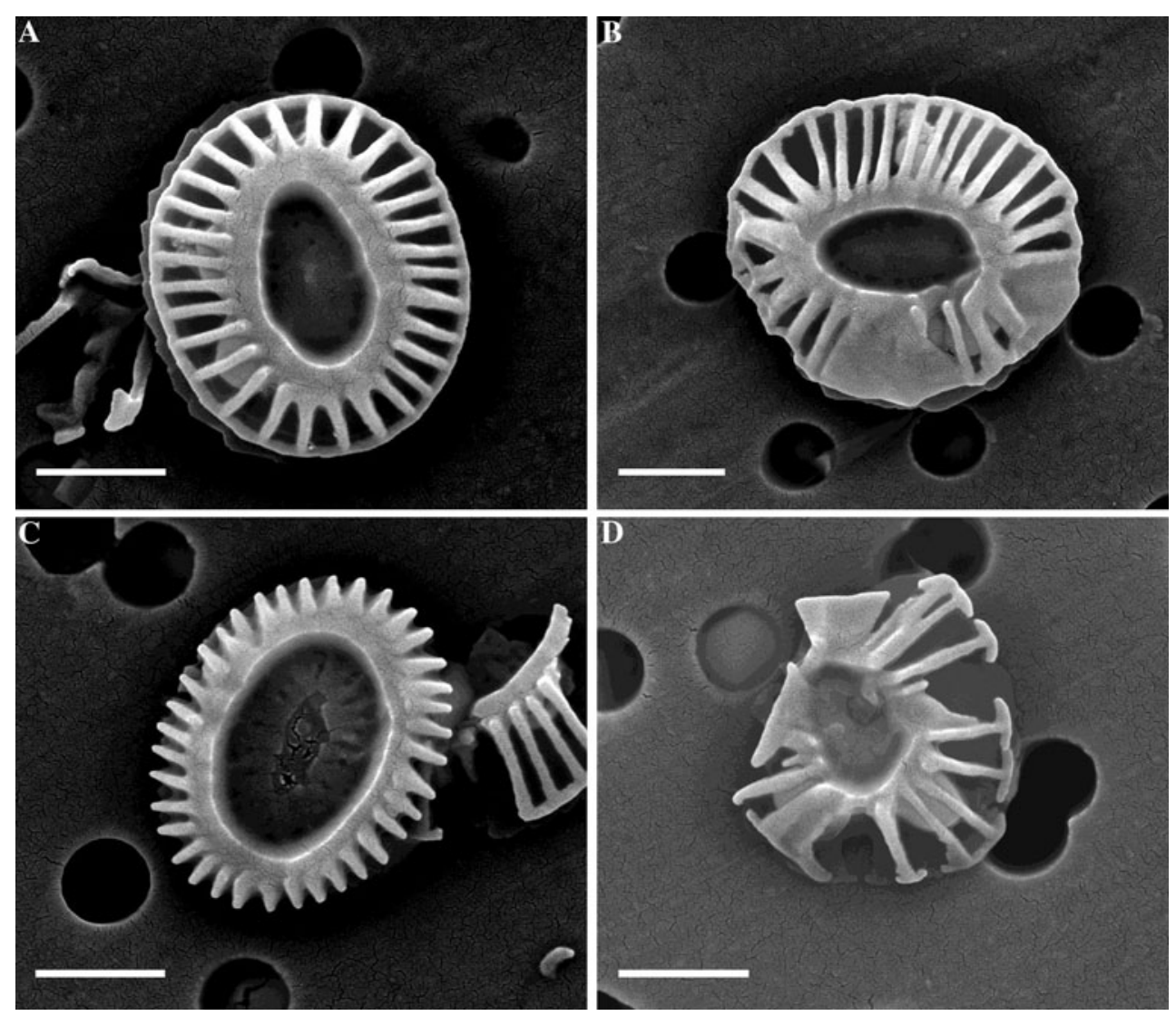

Fig. 2 Scanning electron micrographs of E. huxleyi coccoliths in distal view. a normal, b malformed 1, c incomplete, d malformed 2. All scalebars are $1 \mu \mathrm{m}$ 


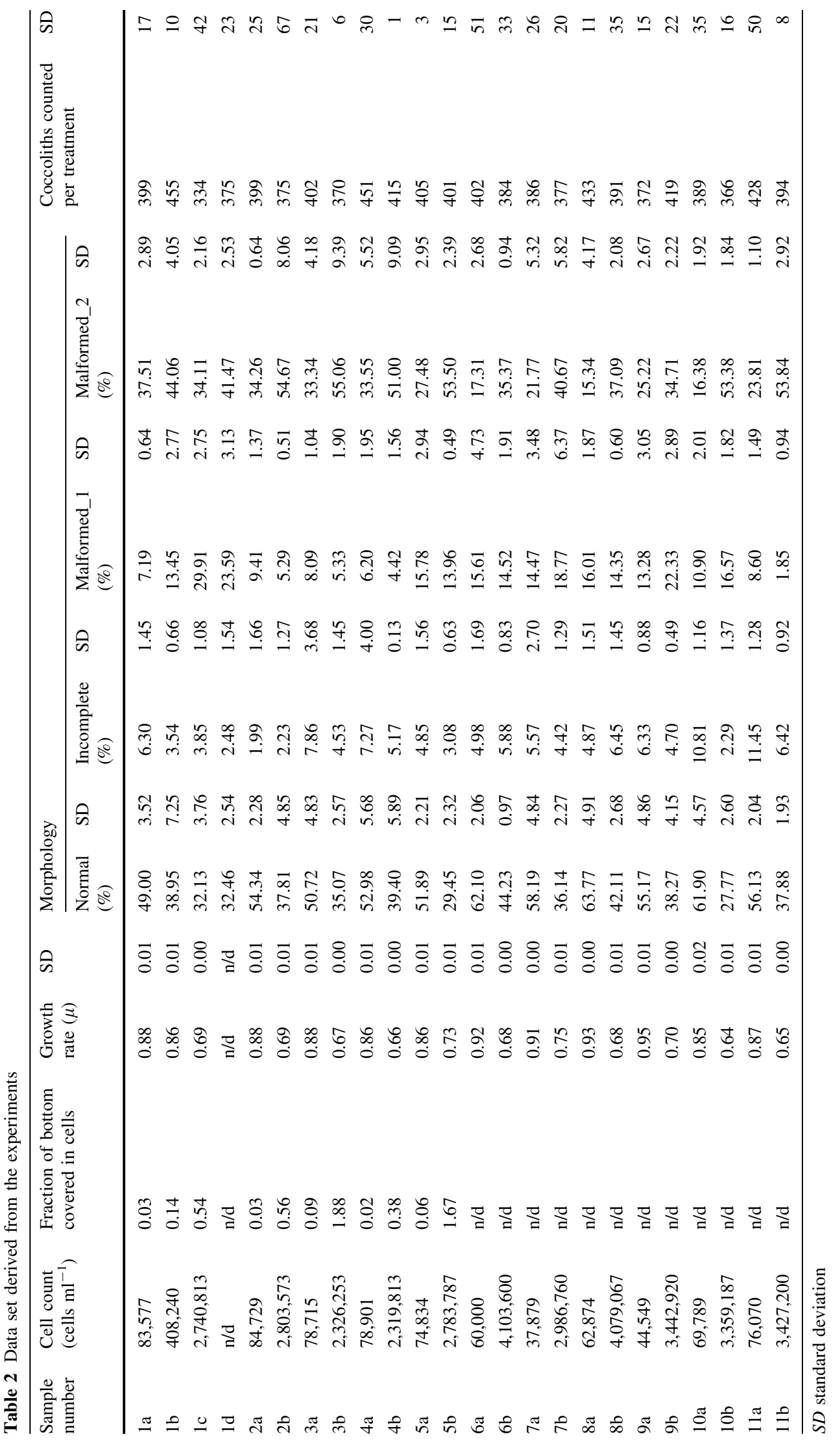


Table 3 Carbonate chemistry

\begin{tabular}{llllllll}
\hline $\begin{array}{l}\text { Sample } \\
\text { number }\end{array}$ & $\begin{array}{l}\mathrm{TA} \\
\left(\mu \mathrm{mol} \mathrm{kg}{ }^{-1}\right)\end{array}$ & $\begin{array}{l}\mathrm{pH} \\
(\text { total scale })\end{array}$ & $\begin{array}{l}\mathrm{DIC} \\
\left(\mu \mathrm{mol} \mathrm{kg}{ }^{-1}\right)\end{array}$ & $\begin{array}{l}\mathrm{pCO}_{2} \\
(\mu \mathrm{atm})\end{array}$ & $\begin{array}{l}\mathrm{HCO}_{3}^{-} \\
\left(\mu \mathrm{mol} \mathrm{kg}^{-1}\right)\end{array}$ & $\begin{array}{l}\mathrm{CO}_{3}^{2-} \\
\left(\mu \mathrm{mol} \mathrm{kg}^{-1}\right)\end{array}$ & $\Omega_{\mathrm{Ca}}$ \\
\hline $1 \mathrm{a}$ & 2,398 & 7.896 & 2,185 & 563 & 2,032 & 133 & 2.77 \\
$1 \mathrm{~b}$ & 2,180 & 8.224 & 1,814 & 207 & 1,585 & 221 & 4.60 \\
$1 \mathrm{c}$ & 1,611 & 9.211 & 761 & 4 & 323 & 438 & 9.09 \\
$1 \mathrm{~d}$ & 1,493 & 8.958 & 806 & 11 & 459 & 347 & 7.21 \\
\hline
\end{tabular}

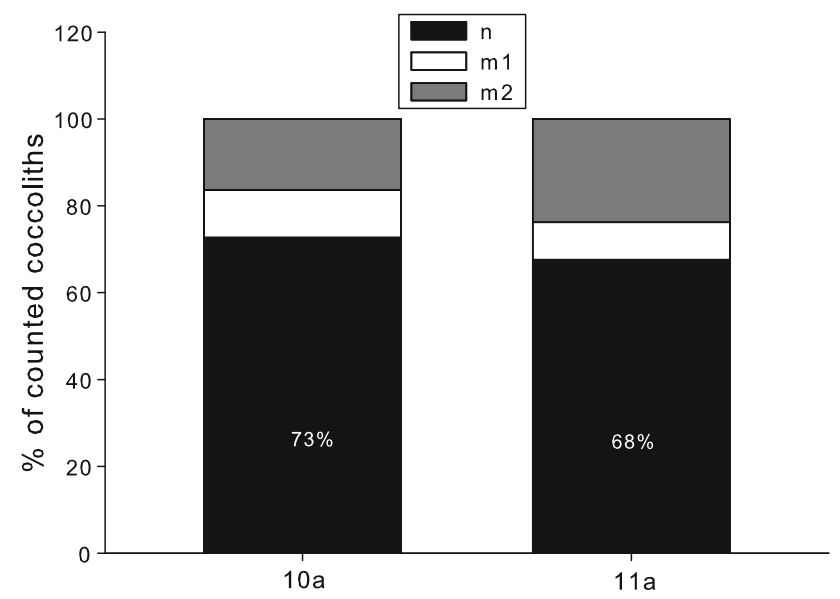

Fig. 3 Coccolith morphology versus sample number. For explanation of sample number, please refer to Table $1 . n$ normal, $m 1$ malformed type $1, m 2$ malformed type $2, i$ incomplete. For reference images, please refer to Fig. 2

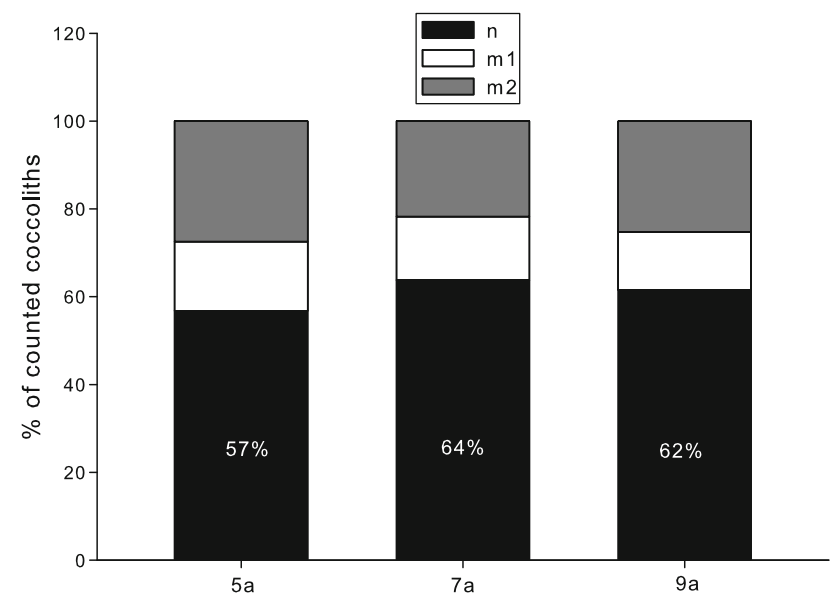

Fig. 4 Coccolith morphology versus sample number. For explanation of sample number, please refer to Table $1 . n$ normal, $m 1$ malformed type $1, m 2$ malformed type 2, $i$ incomplete. For reference images, please refer to Fig. 2

$12 \%$ (continuous mixing) (Fig. 5). Continuous mixing of exponential-phase cells increased the percentage of normal coccoliths by $10 \%$ when performed by a rotating wheel and $12 \%$ when performed by a shaker table (Fig. 6). Continuous mixing of stationary-phase cells increased the percentage of normal coccoliths by $17 \%$ when performed

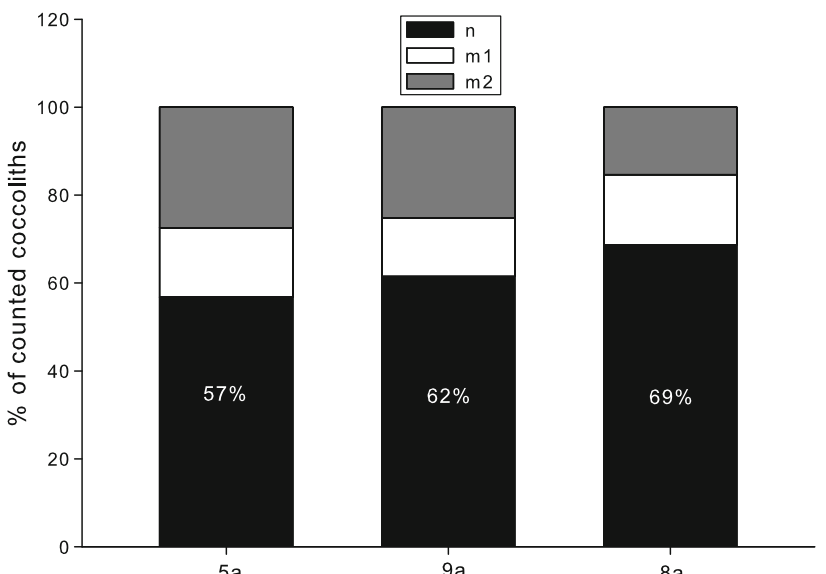

$5 a$

$9 a$

$8 a$

Fig. 5 Coccolith morphology versus sample number. For explanation of sample number, please refer to Table 1. $n$ normal, $m 1$ malformed type 1, $m 2$ malformed type 2, $i$ incomplete. For reference images, please refer to Fig. 2

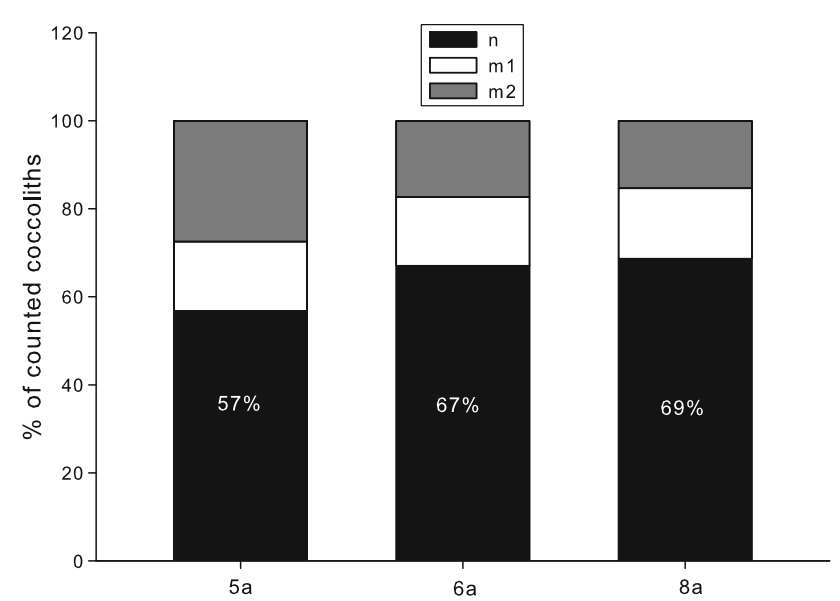

Fig. 6 Coccolith morphology versus sample number. For explanation of sample number, please refer to Table 1. $n$ normal, $m 1$ malformed type $1, m 2$ malformed type $2, i$ incomplete. For reference images, please refer to Fig. 2

by a rotating wheel and $16 \%$ when performed by a shaker table (Fig. 7). Continuously mixed cells displayed $20 \%$ more normal coccoliths in exponential phase than in stationary phase (Fig. 8). Static cells displayed 19\% more normal coccoliths in exponential phase than in stationary phase (Fig. 9). Finally, the percentages of normal coccoliths 


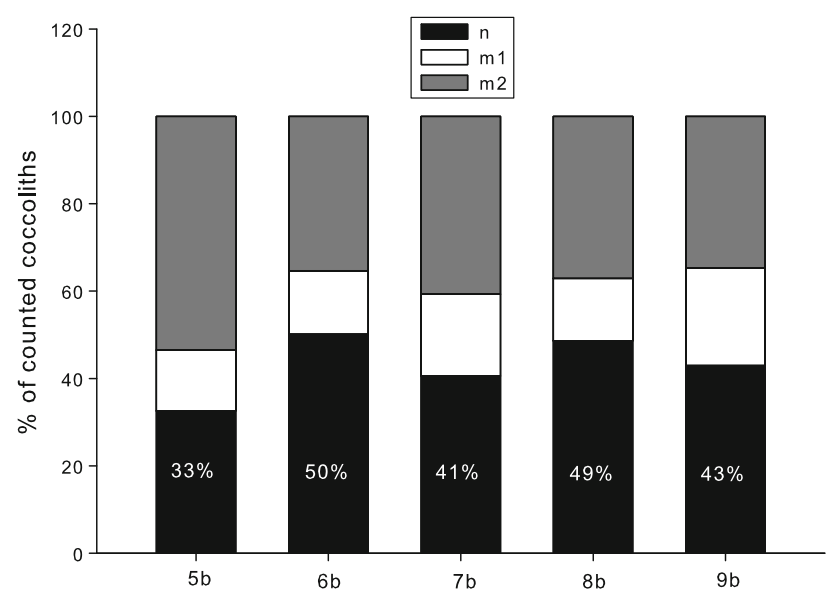

Fig. 7 Coccolith morphology versus sample number. For explanation of sample number, please refer to Table $1 . n$ normal, $m 1$ malformed type $1, m 2$ malformed type $2, i$ incomplete. For reference images, please refer to Fig. 2

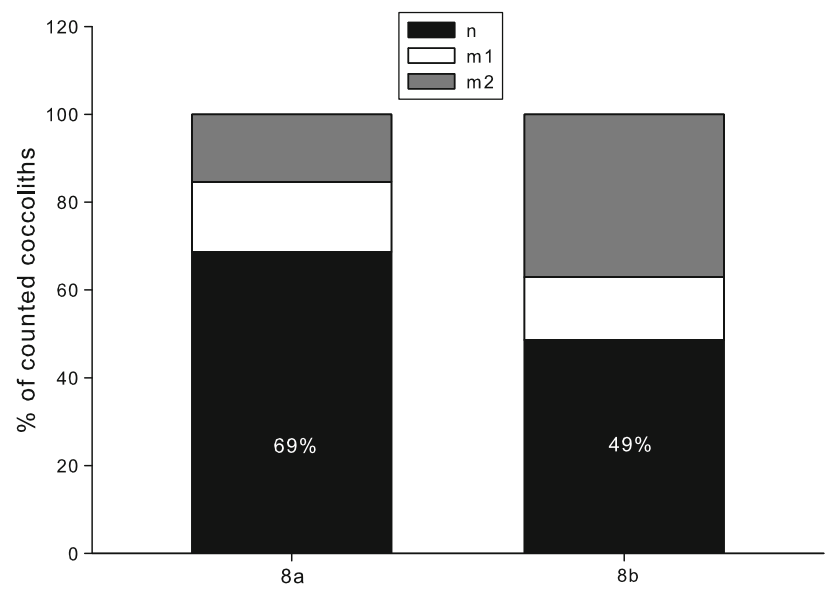

Fig. 8 Coccolith morphology versus sample number. For explanation of sample number, please refer to Table 1. $n$ normal, $m 1$ malformed type $1, m 2$ malformed type $2, i$ incomplete. For reference images, please refer to Fig. 2

in relation to flask bottom area covered in cells will be summarized. We will give fraction of flask bottom area and percentage of normal coccoliths for different treatments: treatment $1 \mathrm{a}, 0.03(55 \%)$; treatment $1 \mathrm{c}, 0.54(36 \%)$; treatment $2 \mathrm{a}, 0.03(56 \%)$; treatment $2 \mathrm{~b}, 0.56(40 \%)$; treatment $3 \mathrm{a}$, 0.09 (59\%); treatment 3b, $1.88(40 \%)$; treatment $4 \mathrm{a}, 0.02$ $(60 \%)$; treatment $4 \mathrm{~b}, 0.38(45 \%)$; treatment $5 \mathrm{a}, 0.06(57 \%)$; and treatment $5 \mathrm{~b}, 1.67(33 \%)$.

\section{Discussion}

Cells of E. huxleyi were grown in different culture flasks (see 'Materials and methods', Fig. 1), both in a static set-up and in motion. Within the latter set-up, we further distinguished between keeping the flasks constantly in motion

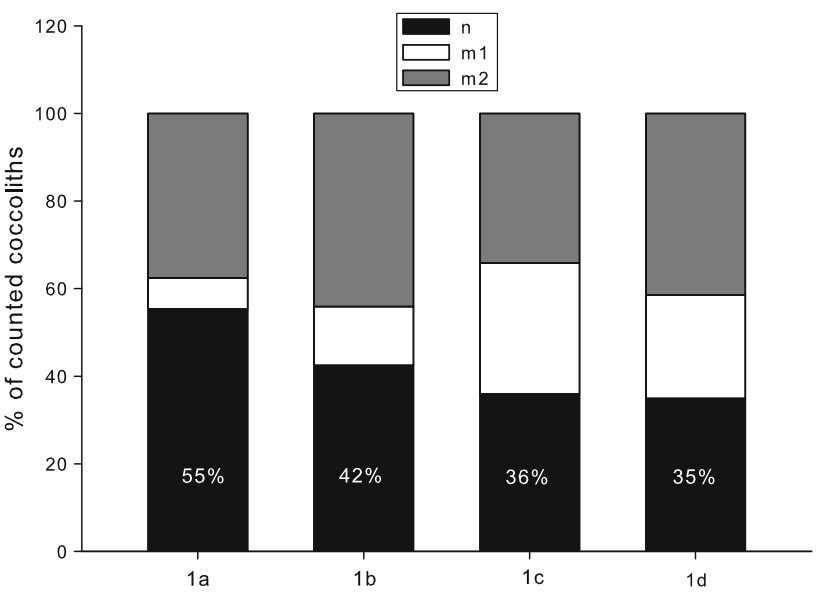

Fig. 9 Coccolith morphology versus sample number. For explanation of sample number, please refer to Table 1. $n$ normal, $m 1$ malformed type $1, m 2$ malformed type $2, i$ incomplete. For reference images, please refer to Fig. 2

and keeping the flasks in motion during the light phase only. All cultures were grown to stationary phase, but sampled also in exponential growth phase. Coccolith morphology data are compiled in Table 2. Sample numbers 1-5 and 10-11 refer to the static set-up, whereas sample numbers 6-9 refer to the cultures kept in motion (Table 1). Experiments 10 and 11 aimed at testing the influence of flask material, that is, polycarbonate (sample number 10) and polystyrene (sample number 11). Cells grown in the latter type of flask produced almost $6 \%$ less normal coccoliths than cells grown in the former (compare 10a with 11a, Fig. 3, Table 2). We are, in general, very cautious in ascribing meaning to a difference of less than $10 \%$ (Langer et al. 2012). Therefore, we regard the difference between polycarbonate and polystyrene as not meaningful. The caution employed here is especially appropriate because there are only two treatments that are compared. There is, consequently, no gradual increase in a potentially influential factor, making it easier to identify effects. The latter is not true with regard to the potential effect of mixing.

While mixing the cells during the light phase only has a less than meaningful (i.e. less than $10 \%$, precisely 4 and $7 \%$, Fig. 4, Table 2) effect on morphology, the constant mixing resulted in a 10 and $12 \%$ increase in the percentage of normal coccoliths (Figs. 5, 6). Therefore, we conclude that mixing has a small but discernible effect on coccolith morphogenesis. Please note that the same trend can be seen in the stationary-phase samples, where it is slightly more pronounced, that is, 16 and $17 \%$ (Fig. 7). While the effect of mixing is modulated by cell density, the latter itself has an effect on morphogenesis. The percentage of normal coccoliths decreases with increasing cell density as can be observed in mixed cultures (Fig. 8) as well as in static 
cultures (Fig. 9). Interestingly, the cell density effect is equally big in mixed (20\%, Fig. 8) and static (19\%, Fig. 9) cultures. This implies that cell density and mixing independently affect morphogenesis. Please note that the cell density for treatment $1 \mathrm{~d}$ was not determined (and consequentially no fraction of flask bottom covered in cells can be given). Since the cells were already in stationary phase (treatment 1c), a change in cell density could only have arisen from disintegration of dead cells. Whether this actually happened or not, however, is irrelevant for the comparison between $1 \mathrm{c}$ and $1 \mathrm{~d}$, which shows that 3 weeks in stationary phase do not lead to an increase in malformations, although it is likely that some coccoliths were produced as inferred from the consumption of $118 \mu \mathrm{mol}$ $\mathrm{kg}^{-1}$ of TA (see Table 3 ).

It is not possible to explain the effects of both mixing and cell density in terms of an unfavourable microenvironment as detailed in the following. It is tempting to assume that cells that sit in stacks on the bottom of a culture flask create a microenvironment around themselves, which is depleted in necessary ions and/or molecules, for example, nutrients, and enriched in toxic waste products. The higher the cell density and/or the less efficient the mixing, the bigger the difference between the microenvironment and the bulk water chemistry would be. While it is possible, though not free of difficulties, to explain the effect of mixing in terms of a microenvironment (see below), this explanation cannot hold for the cell density effect. The latter is as pronounced in mixed cultures as in static ones (Figs. 8,9), clearly implying that a microenvironment, which is absent in mixed cultures, cannot be involved in causing the effect.

If a microenvironment was crucial to understanding the effect of mixing, it would be reasonable to assume that the effect is more pronounced in higher cell stacks. This issue can be assessed by comparing the effect of different culture flasks and different positions (horizontal or vertical) of one flask. These various set-ups result in different culture volume to flask-bottom-area ratios and therewith in different fractions of flask bottom covered in cells (Table 2). A fraction of 1 indicates one single layer of cells, a fraction of 2 means two layers, and so on. Only in two cases (samples $3 \mathrm{~b}$ and $5 \mathrm{~b}$, Table 2 ) did the fraction exceed unity, not even reaching 2 . This means that, counter-intuitively, cells in a standard stock culture (treatment 2, Table 1 is probably most common) are not stacked, even in stationary phase. While multi-layers of cells would most likely lead to a microenvironment around the cells noticeably different from the bulk water, it is questionable whether this would be the case in an incomplete mono-layer. Judging from our morphological data only the influence of a microenvironment might be inferred, but it is highly unlikely that this is the main reason for the effect of mixing as detailed below.
Firstly, the cell density effect is slightly bigger in treatments 3 (19\%, Table 2) and 5 (24\%, Table 2) (fraction of flask bottom covered in cells maximally 1.88 and 1.67) than in treatments 1 (19\%, Table 2), 2 (16\%, Table 2), and 4 (16\%, Table 2) (fraction of flask bottom covered in cells maximally $0.54,0.56$, and 0.38 ). This observation might point to a bigger influence of the microenvironment with increasing flask area covered in cells. As a caveat, please note that the cell density effect is as big in treatment 3 (19\%, Table 2) as it is in treatment 1 (19\%, Table 2). However, if the above interpretation was correct, it would be inexplicable why the cell density effect is equally big in mixed and static cultures (Figs. 8, 9). Secondly, the effect of mixing is slightly bigger in stationary-phase samples as opposed to exponential-phase samples (4-7\% difference, Figs. 6 and 7), which, again, might point to the influence of a microenvironment. Whether the small difference (4-7\%, Figs. 6, 7) between exponential and stationary-phase samples justifies this interpretation is questionable. On a minor note, mixing also increases growth rate by ca. $6 \%$ and stationary-phase cell density by ca. $30 \%$ (Table 2). Although intuitive, it remains enigmatic why exactly mixing is beneficial to the cells.

A similar conclusion can be drawn with regard to the cell density effect. The latter is noticeable when comparing mid- to late-exponential-phase cultures (Fig. 9) and conspicuous when comparing mid-exponential to stationaryphase cultures (Fig. 9). While it is certain that the cells alter the seawater chemistry through growing, it is far from obvious, which specific alteration could cause the increase in malformations. A shortage of macro-nutrients and trace metals included in the $\mathrm{f} / 2$ supplement (see 'Materials and methods') is out of question, because the concentrations are too high. A particularly sensitive system in seawater is the carbonate system. In order to assess the potential effect of carbonate chemistry alterations, we determined the carbonate system in experiment 1 (Table 3). It is well known that $E$. huxleyi is moderately sensitive to seawater acidification (for a recent overview, see Hoppe et al. 2011); this sensitiveness also includes coccolith morphology (Langer et al. 2011). However, E. huxleyi shifts the carbonate system towards higher $\mathrm{pH}$ through growth (Table 3). A carbonate chemistry characterizing sample $1 \mathrm{~b}$ has never been shown to cause malformations, but the latter are noticeable (13\% increase) in comparison with sample 1a (Fig. 9). We therefore conclude that the cell density effect is not a carbonate chemistry effect. We believe that this conclusion also holds for the stationary-phase samples, although a caveat here is that coccolith morphology in response to such an extensive DIC consumption has never been studied. The continuity of the late-exponential and stationary-phase results, however, leads us to assume a common cause other than carbonate chemistry. 
What then can the cause of the cell density effect be? It is surely possible that some essential compound not included in the $\mathrm{f} / 2$ supplement is consumed and hence becomes limiting. An alternative possibility would be the accumulation of a toxic waste product. Whatever the explanations for the effects of cell density and mixing are, it can on the one hand safely be concluded that these effects are partly responsible for culture artefacts in coccolith morphology. Static cells and cell densities of $>10^{6}$ cells per $\mathrm{ml}$ are purely artificial, that is,. do not occur in nature. On the other hand, it is highly unlikely that these two effects are solely responsible for culture artefacts. In a culture study in which four strains of E. huxleyi were grown under identical conditions, one strain was characterized by a morphology considerably different from that of the others (Langer et al. 2011). So, it seems as if morphology was also strain specific. While this might well be true, it is not the complete story either. One single strain of Calcidiscus leptoporus, grown under almost identical conditions on four occasions over the last decade, displayed considerably different morphologies (Langer et al. 2006; Langer and Bode 2011; Langer et al. 2012). In the most recent study (Langer et al. 2012), a mixture of artificial and natural seawater was used, which might explain the stark contrast to the study carried out a couple of months earlier (Langer and Bode 2011). We do not think that this explanation is sufficient, because a similar level of malformations was observed in the respective culture immediately before the experiment when the cells were grown in natural seawater. Anyhow, it can be concluded that the morphology of a single strain grown under similar conditions changes over time. The timescale of this change is long compared with the timescale of a typical culture experiment and therefore does not impair the latter (Langer et al. 2006).

On the whole, the effects of mixing and cell density described here, although clearly detectable, are weak compared with differences in morphology often observed in cultured specimens of different species (e.g. Langer and Benner 2009). Besides the highly probable possibility that culture artefacts are caused by a multitude of (interdependent?) causes, it should be mentioned that E. huxleyi is the most robust coccolithophore species in culture. Regular observations of stock cultures over the last decade have clearly shown that other species, for example, C. leptoporus and Coccolithus braarudii, more often than not display a percentage of malformations clearly different from the one that can be found in typical sea surface water samples, whereas E. huxleyi often displays a morphology not noticeably different from the one of natural samples. We expect that the effect of mixing and cell density will be more pronounced in more delicate species. Since we tested only two materials, it remains an open question whether the culture flask material in general could have an effect on morphology.

Acknowledgments Thanks to Susanne Spahic and Erika Allhusen for technical assistance. This work was supported by the European Commission through grant 211384 (EU FP7 "EPOCA"). Financial support for BIOACID was provided by the German Federal Ministry of Education and Research (BMBF, FKZ 03F0608). The research leading to these results has received funding from the European Community's Seventh Framework Programme under grant agreement 265103 (Project MedSeA). This work was funded in part by The European Research Council (ERC grant 2010-NEWLOG ADG$267931 \mathrm{HE})$.

\section{References}

Bach LT, Bauke C, Meier KJS, Riebesell U, Schulz KG (2012) Influence of changing carbonate chemistry on morphology and weight of coccoliths formed by Emilianiahuxleyi. Biogeosciences 9:3449-3463. doi:10.5194/bg-9-3449-2012

Baumann K-H, Böckel B, Frenz M (2004) Coccolith contribution to South Atlantic carbonate sedimentation. In: Thierstein HR, Young JR (eds) Coccolithophores-from molecular processes to global impact. Springer, Berlin/Heidelberg, pp 367-402

Birkenes E, Braarud T (1952) Phytoplankton in the Oslo Fjord during a 'Coccolithus huxleyi-summer'. Avh Nor Viden Akad Oslo 1952(2):1-23

Bradshaw AL, Brewer PG, Shaffer DK, Williams RT (1981) Measurements of total carbon dioxide and alkalinity by potentiometric titration in the GEOSECS program. Earth Planet Sci Lett 55:99-115

Brewer PG, Bradshaw AL, Williams RT (1986) Measurement of total carbon dioxide and alkalinity in the North Atlantic ocean in 1981. In: Trabalka JR, Reichle DE (eds) The changing carbon cycle-a global analysis. Springer, New York, pp 358-381

Dickson AG (2010) The carbon dioxide system in sea water: equilibrium chemistry and measurements. In: Riebesell U, Fabry VJ, Hansson L, Gattuso J-P (eds) Guide for best practices in ocean acidification research and data reporting. Office for Official Publications of the European Union, Luxembourg, pp $17-40$

Dickson AG, Millero FJ (1987) A comparison of the equilibrium constants for the dissociation of carbonic acid in seawater media. Deep Sea Res 34:1733-1743

Gran G (1952) Determination of the equivalence point in potentiometric titrations of seawater with hydrochloric acid. Oceanol Acta 5:209-218

Guillard RRL, Ryther JH (1962) Studies of marine planktonic diatoms, I, Cyclotella nanna (Hustedt) and Detonula convervacea (Cleve). Can J Microbiol 8:229-239

Hoppe CJM, Langer G, Rost B (2011) Emiliania huxleyi shows identical responses to elevated pCO2 in TA and DIC manipulations. J Exp Mar Biol Ecol 406:54-62

Langer G, Benner I (2009) Effect of elevated nitrate concentration on calcification in Emiliania huxleyi. J Nannoplankton Res 30: $77-80$

Langer G, Bode $\mathrm{M}$ (2011) $\mathrm{CO}_{2}$ mediation of adverse effects of seawater acidification in Calcidiscus leptoporus. Geochem Geophys Geosyst 12:Q05001. doi:05010.01029/02010GC003393

Langer G, Geisen M, Baumann K-H, Kläs J, Riebesell U, Thoms S, Young JR (2006) Species-specific responses of calcifying algae to changing seawater carbonate chemistry. Geochem Geophys Geosyst 7:Q09006. doi:09010.01029/02005GC001227 
Langer G, Gussone N, Nehrke G, Riebesell U, Eisenhauer A, Thoms $S$ (2007) Calcium isotope fractionation during coccolith formation in Emiliania huxleyi: independence of growth and calcification rate. Geochem Geophys Geosyst 8:Q05007. doi: 05010.01029/02006GC001422

Langer G, de Nooijer LJ, Oetjen K (2010) On the role of the cytoskeleton in coccolith morphogenesis: the effect of cytoskeleton inhibitors. J Phycol 46:1252-1256

Langer G, Probert I, Nehrke G, Ziveri P (2011) The morphological response of Emiliania huxleyi to seawater carbonate chemistry changes: an inter-strain comparison. J Nannoplankton Res 32:27-32

Langer G, Oetjen K, Brenneis T (2012) Calcification of Calcidiscus leptoporus under nitrogen and phosphorus limitation. J Exp Mar Biol Ecol 413:131-137

Lewis E, Wallace DWR (1998) Program developed for $\mathrm{CO}_{2}$ system calculations ORNL/CDIAC-105. Carbon Dioxide Information Analysis Centre, Oak Ridge National Laboratory, U.S. Department of Energy, Oak Ridge, Tennessee

Mehrbach C, Culberson CH, Hawley JE, Pytkovicz RM (1973) Measurement of the apparent dissociation constants of carbonic acid in seawater at atmospheric pressure. Limnol Oceanogr 18: 897-907
Probert I, Houdan A (2004) Laboratory culture of coccolithophores. In: Thierstein HR, Young JR (eds) Coccolithophores-from molecular processes to global impact. Springer, Berlin/Heidelberg, pp 217-250

Riebesell U, Zondervan I, Rost B, Tortell PD, Zeebe RE, Morel FMM (2000) Reduced calcification of marine plankton in response to increased atmospheric $\mathrm{CO}_{2}$. Nature 407:364-367

Royal Society (2005) Ocean acidification due to increasing atmospheric carbon dioxide. Policy Document 12/05. The Royal Society, London

Stoll MHC, Bakker K, Nobbe GH, Haese RR (2001) Continuous-flow analysis of dissolved inorganic carbon content in seawater. Anal Chem 73:4111-4116

Watabe N, Wilbur KM (1966) Effects of temperature on growth, calcification, and coccolith form in Coccolithus huxleyi (Coccolithineae). Limnol Oceanogr 11:567-575

Young J (1994) Variation in Emiliania huxleyi coccolith morphology in samples from the Norwegian EHUX mesocosm experiment, 1992. Sarsia 79:417-425

Young JR, Westbroek P (1991) Genotypic variation in the coccolithophorid species Emiliania huxleyi. Mar Micropaleontol 18: 5-23 